\title{
Transcutaneous electrical nerve stimulation (TENS) for pain management in sickle cell disease
}

\author{
Sudipta Pal \\ Melaka Manipal Medical College \\ Ruchita Dixit \\ Melaka Manipal Medical College \\ Soe Moe \\ Melaka Manipal Medical College \\ Myron A. Godinho \\ Manipal University

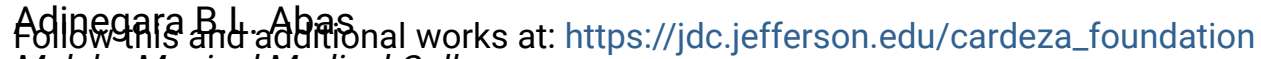 \\ Melaka Manipal Medical College \\ Part of the Hematology Commons \\ Let us know how access to this document benefits you
}

\section{Recommended Citation}

Pal, Sudipta; Dixit, Ruchita; Moe, Soe; Godinho, Myron A.; Abas, Adinegara B.L.; Ballas, Samir K.; Ram, Shanker; and Yousuf, Uduman A.M., "Transcutaneous electrical nerve stimulation (TENS) for pain management in sickle cell disease" (2017). Cardeza Foundation for Hematologic

Research. Paper 44.

https://jdc.jefferson.edu/cardeza_foundation/44

This Article is brought to you for free and open access by the Jefferson Digital Commons. The Jefferson Digital Commons is a service of Thomas Jefferson University's Center for Teaching and Learning (CTL). The Commons is a showcase for Jefferson books and journals, peer-reviewed scholarly publications, unique historical collections from the University archives, and teaching tools. The Jefferson Digital Commons allows researchers and interested readers anywhere in the world to learn about and keep up to date with Jefferson scholarship. This article has been accepted for inclusion in Cardeza Foundation for Hematologic Research by an authorized administrator of the Jefferson Digital Commons. For more information, please contact: JeffersonDigitalCommons@jefferson.edu. 


\section{Authors}

Sudipta Pal, Ruchita Dixit, Soe Moe, Myron A. Godinho, Adinegara B.L. Abas, Samir K. Ballas, Shanker Ram, and Uduman A.M. Yousuf 


\section{Cochrane Library}

Cochrane Database of Systematic Reviews

\section{Transcutaneous electrical nerve stimulation (TENS) for pain management in sickle cell disease (Protocol)}

Pal S, Dixit R, Moe S, Godinho MA, Abas ABL, Ballas SK, Ram S, Yousuf UAM

Pal S, Dixit R, Moe S, Godinho MA, Abas ABL, Ballas SK, Ram S, Yousuf UAM.

Transcutaneous electrical nerve stimulation (TENS) for pain management in sickle cell disease.

Cochrane Database of Systematic Reviews 2017, Issue 8. Art. No.: CD012762.

DOI: 10.1002/14651858.CD012762.

www.cochranelibrary.com 
TABLE OF CONTENTS

HEADER . . . . . . . . . . . . . . . . . . . . . . . . . . . . . . . . . . . . 1

ABSTRACT . . . . . . . . . . . . . . . . . . . . . . . . . . . . . . . . . . . . . . . . . .

BACKGROUND . . . . . . . . . . . . . . . . . . . . . . . . . . . . . . . . . . . .

OBJECTIVES . . . . . . . . . . . . . . . . . . . . . . . . . . . . . . . . . . . . . . .

METHODS . . . . . . . . . . . . . . . . . . . . . . . . . . . . . . . . . . . . . .

ACKNOWLEDGEMENTS . . . . . . . . . . . . . . . . . . . . . . . . . . . . . . . . . . . . . . . .

REFERENCES . . . . . . . . . . . . . . . . . . . . . . . . . . . . . . . . . . . . . . .

APPENDICES . . . . . . . . . . . . . . . . . . . . . . . . . . . . . . . . . . . . . 9

CONTRIBUTIONS OF AUTHORS . . . . . . . . . . . . . . . . . . . . . . . . . . . . . . . . . . . . . . . . . .

DECLARATIONS OF INTEREST . . . . . . . . . . . . . . . . . . . . . . . . . . . . . . . . 12

SOURCES OF SUPPORT . . . . . . . . . . . . . . . . . . . . . . . . . . . . . . . . . . . . . . . . .

Transcutaneous electrical nerve stimulation (TENS) for pain management in sickle cell disease (Protocol)

Copyright $\odot 2017$ The Cochrane Collaboration. Published by John Wiley \& Sons, Ltd. 


\title{
[Intervention Protocol]
}

\section{Transcutaneous electrical nerve stimulation (TENS) for pain management in sickle cell disease}

\author{
Sudipta Pal ${ }^{1}$, Ruchita Dixit ${ }^{1}$, Soe $\mathrm{Moe}^{2}$, Myron A Godinho ${ }^{3}$, Adinegara BL Abas ${ }^{1}$, Samir K Ballas ${ }^{4}$, Shanker Ram ${ }^{5}$, Uduman Ali M \\ Yousuf $^{6}$ \\ ${ }^{1}$ Department of Community Medicine, Melaka-Manipal Medical College, Melaka, Malaysia. ${ }^{2}$ Department of Community Medicine, \\ Faculty of Medicine, Melaka, Malaysia. ${ }^{3}$ Public Health Evidence South Asia (PHESA), Manipal University, Manipal, India. ${ }^{4}$ Cardeza \\ Foundation for Hematologic Research, Department of Medicine, Jefferson Medical College, Thomas Jefferson University, Philadelphia, \\ USA. ${ }^{5}$ Department of Psychiatry, Melaka Manipal Medical College, Melaka, Malaysia. ${ }^{6}$ Department of Medicine, Melaka Manipal \\ Medical College, Melaka, Malaysia
}

Contact address: Sudipta Pal, Department of Community Medicine, Melaka-Manipal Medical College, Jalan Batu Hampar, Bukit Baru, Melaka, 75150, Malaysia. sudipta_paul@yahoo.com.

Editorial group: Cochrane Cystic Fibrosis and Genetic Disorders Group.

Publication status and date: New, published in Issue 8, 2017.

Citation: Pal S, Dixit R, Moe S, Godinho MA, Abas ABL, Ballas SK, Ram S, Yousuf UAM. Transcutaneous electrical nerve stimulation (TENS) for pain management in sickle cell disease. Cochrane Database of Systematic Reviews 2017, Issue 8. Art. No.: CD012762. DOI: 10.1002/14651858.CD012762.

Copyright (C) 2017 The Cochrane Collaboration. Published by John Wiley \& Sons, Ltd.

\section{A B S T R A C T}

This is a protocol for a Cochrane Review (Intervention). The objectives are as follows:

To assess the effects of TENS for managing pain in people with SCD who experience pain crises or chronic pain (or both), along with any possible adverse effects.

\section{B A C K G R O U N D}

\section{Description of the condition}

Please refer to the glossary for the explanation of clinical terms (Appendix 1).

Sickle cell disease (SCD) encompasses a host of genetically inherited disorders in which red blood cells become increasingly deformed and friable, causing vaso-occlusion and haemolysis. This disease is one of the most common, severe, single gene mutation (monogenic) disorders (Weatherall 2001).

The disease is most prevalent in sub-Saharan Africa, affecting an estimated 230,000 children born regionally every year - account- ing for $80 \%$ of the total global incidence (David 2010). In the USA, it affects around 100,000 people, predominantly those of African descent. The disease occurs in about one in every 500 African-American births and one in every 1000 to 1400 HispanicAmerican births. Approximately two million Americans, or one in 12 African Americans, carry the sickle cell allele (WHO 2015). This geographical predominance corresponds to an adaptive advantage: heterozygous carriers (sickle cell trait) are naturally resistant to infection by the endemic Plasmodium falciparum ( $P$ falciparum) malarial parasite (Barbedo 1974).

The vaso-occlusive crisis (VOC) is the hallmark of the disease and is often unpredictable, varies in quality, duration, location and severity, and can be precipitated by known and unknown 
factors (Ballas 2005). Vaso-occlusive pain episodes are the most common cause of recurrent morbidity, hospital admissions and work or school absenteeism in people with SCD (Platt 1991). Approximately $90 \%$ of hospital admissions of people with SCD are for treating acute pain (Brozovic 1987). Hypoxia, dehydration, acidosis, cold exposure and strenuous exercise also can lead to sickling of red blood cells leading to an acute painful episode.

Nociceptive sickle cell pain may be acute recurrent painful crises, chronic pain syndromes and neuropathic pain. The acute painful crisis evolves through prodromal, initial, established and resolving phases (Ballas 2012). Chronic sickle cell pain may be due to avascular necrosis and leg ulcers or intractable pain without any obvious signs. Chronic pain is usually associated with emotional distress, behavioural dysfunction, family stress, financial concern, frequent visits to healthcare providers, heavy use of analgesic medications and fear (Ballas 2005).

Treatment aims for SCD are to relieve pain, prevent infections and manage complications (Stinson 2003). Despite being the main source of discomfort for people with SCD, therapies for pain crises are not definitive. Pharmacotherapies involve opioids, nonopioids and adjuvants. Non-opioids (e.g. acetaminophen, nonsteroidal anti-inflammatory drugs (NSAIDs) tramadol and corticosteroids) have a 'ceiling effect' beyond which they are no longer effective, and NSAIDs and corticosteroids have well-known complications such as haemostasis, acute renal failure, congestive heart failure when overused (Niscola 2009). Thus opioids are frequently employed, as they have fewer systemic effects. However, their use is plagued with reports of addiction, tolerance and drug-seeking behaviour (Neville 2011). Moreover, opioids may contribute to the development of acute chest syndrome during an acute sickle cell pain crisis (Buchanan 2005).

These factors have motivated clinicians and researchers worldwide to embrace a multidisciplinary approach towards pain management in people with SCD, with a focus on including non-pharmacological interventions. According to the recommendations of the American Pain Society, pharmacological treatments for SCD should be complimented by psychological, behavioral, and physical modalities (American Pain Society Guidelines 1999).

\section{Description of the intervention}

As defined by the American Physical Therapy Association, TENS is the application of electrical stimulation to the skin for pain control. It is non-invasive, inexpensive, safe, and easy to use; a small battery-powered device applies an electric current via two or more non-invasive skin electrodes to stimulate underlying nerves and thus reduce pain perception. It can be applied with different frequencies, varying from low $(<10 \mathrm{~Hz})$ to high $(>50 \mathrm{~Hz})$. Intensity can also vary with low-intensity stimulation producing a sensation alone, while high-intensity stimulation triggers muscle contraction, and hence movement. Low-frequency TENS is usually given at high-intensity (producing motor contraction and sensation), while high-frequency TENS is given at lower intensities (producing both sensation and muscle contraction) (DeSantana 2008). Conventional TENS has a high-stimulation frequency $(40 \mathrm{~Hz}$ to $150 \mathrm{~Hz}$ ) and low intensity between $10 \mathrm{~mA}$ to $30 \mathrm{~mA}$. The pulse duration is short (up to 50 microseconds). The onset of analgesia with this setup is virtually immediate. Pain relief lasts while the stimulus is turned on, but it usually abates when the stimulation stops. In acupuncture like settings, the TENS unit delivers low frequency stimulus trains at $1 \mathrm{~Hz}$ to $10 \mathrm{~Hz}$, at a high stimulus intensity, close to the tolerance limit of the individual. This method is uncomfortable and is often considered for those who do not respond to conventional TENS. Pulsed (burst) TENS uses lowintensity stimuli firing in high-frequency bursts, but does not have any added advantage over the conventional method.

Over the last 40 years, TENS has been evaluated for the management of pain in numerous conditions, including fibromyalgia (Sunshine 1996) rheumatoid arthritis, osteoarthritis, post-caesarean pain, lower back pain (Milne 2004) neck pain and numerous other causes. While reviews report that evidence on the efficacy of TENS is inconclusive, magnetic resonance imaging (MRI) studies implicate central pain signal modulation indicating a central action (Kocyigit 2012). There are contraindications for the use of TENS. These include use during pregnancy, as it may induce premature labour, as well as application over the carotid sinuses, due to the risk of acute hypotension through a vasovagal reflex. In addition to these, it should not be placed over the anterior neck, because laryngospasm due to laryngeal muscle contraction may occur, the electrodes should not be placed in an area of sensory impairment, where the possibility of burns exists and a TENS unit should be used cautiously in individuals with a spinal cord stimulator or an intrathecal pump.

\section{How the intervention might work}

A variety of mechanisms for the analgesic action of TENS have been suggested, including presynaptic inhibition in the dorsal horn of the spinal cord, endogenous pain control via endorphins, and direct inhibition of nerve excitation and restoration of afferent input (Kaye 2015). This produces a host of responses, including sensation, movement (muscle contraction), and pain relief. In people with SCD, vaso-occlusion leads to secondary tissue injury which generates several major pain mediators like interleukin-1, bradykinin which in turn sensitize peripheral nerve endings and facilitate the transmission of painful stimuli along A- $\delta$ and C fibres that reach the cerebral cortex via the spinal cord and the thalamus (Ballas 2005). This partly corresponds to the 'gate control theory' (Melzack 1965) for the mechanism of analgesia produced by TENS where the 'open gate' between $\mathrm{C}$ fibres and T cells which allow pain transmission centrally is closed by the electrical stimulation to the skin provided by the TENS instrument. 


\section{Why it is important to do this review}

Over recent years, although considerable knowledge has been gained on the pathophysiological mechanisms of pain and the pharmacogenetics of analgesics (including opioids) there has been not much progress in the clinical management of sickle cell pain. Many adults with SCD still face accusations, assumptions and disbelief about their painful condition which is often wrongly perceived by some healthcare providers as drug-seeking behaviour (Ballas 2014). Mismanagement of pain in SCD may lead to serious psychosocial and physiological consequences, such as depression, low self esteem, anxiety and reduced participation in social activities, resulting in chronic pain interspersed with episodes of acute exacerbations (Smith 2005). Hence, organizations such as the American Pain Society recommended that pharmacologic treatment for SCD should be complemented by complementary and alternative medicine.

Cochrane Reviews on TENS for specific chronic pain conditions have suggested that TENS is more effective than placebo TENS, although methodological weaknesses in randomised controlled trials (RCTs) have sometimes hindered definitive conclusions (Bennett 2011; Brosseau 2003; Johnson 2010; Rutjes 2009). Studies carried out on the effect of TENS on neck pain suggested that active TENS may be more effective than placebo TENS (Kroeling 2013). A systematic review on the effect of TENS on cancer pain in adults suggested bone pain on movement may improve in a cancer population on application of TENS, but most of the results remained inconclusive due to a limited number of RCTs included in the review (Hurlow 2012).

Most reviews of TENS therapy are inconclusive at present, which is why a standardised, rigorous search and a Cochrane Review are required in this disease area. This issue is further compounded by the practical need to manage the acute pain crises, as well as chronic pain conditions, experienced by millions of people with SCD worldwide. Current pharmacological therapies produce too many unacceptable side effects, and as already stated, recommendations encourage the use of non-pharmacological methods in SCD pain management. A Cochrane Review of the current evidence regarding the effectiveness of TENS as a complementary therapy for managing pain in people with SCD will allow health professionals and researchers make informed decisions about the use of this treatment.

\section{O B JEC T IVES}

To assess the effects of TENS for managing pain in people with SCD who experience pain crises or chronic pain (or both), along with any possible adverse effects.

\section{Criteria for considering studies for this review}

\section{Types of studies}

RCTs. Quasi-RCTs will also be included if sufficient evidence is provided to demonstrate that the treatment and control groups are similar at baseline.

In reference to cross-over trials, as we are currently unaware of the long-term effects of these interventions, we are unable to determine whether the effects of the first intervention will interfere with those of the second. In order to avoid introducing this bias into the analysis, we will include only first-arm data from crossover trials, when available.

\section{Types of participants}

People with known SCD (SS, SC, $\mathrm{S} \beta^{+}$and $\mathrm{S} \beta^{0}$, proven by electrophoresis and sickle solubility test, with family studies or DNA tests as appropriate) of all ages and both sexes, in any setting.

\section{Types of interventions}

We will include all standard modes of TENS which includes biphasic or monophasic electrical current delivered in pulses in high frequency, low intensity or low frequency, high intensity or other standard modes that produce perceptible sensation at the area of application. We will exclude other modes of electrotherapy, TENS that was delivered in intensities that were barely perceptible.

Eligible comparisons are:

- TENS with conventional treatment (e.g. analgesics) versus conventional treatment alone;

- TENS versus placebo (sham) TENS;

- TENS versus other non-pharmacological modalities for treatment of pain.

We do not plan to compare different intensities and frequencies of TENS as all standard modes of TENS which produce perceptible sensation at the area of application will be included in this review. Placebo (sham) TENS devices may look exactly similar to active TENS devices, but are deactivated and produce no current or may produce a brief period of stimulation at the beginning which fades out later. Due to the lack of perceptible stimulation in SHAM TENS, blinding of participants to the mode of treatment is almost impossible (Sluka 2013) and this represents a risk of bias to all sham-controlled trials of TENS (Gibson 2015).

\section{Types of outcome measures}

\section{Primary outcomes}

1. Pain relief*

\section{METHODS}


2. Pain intensity (as assessed by visual analogue pain scale score (VAS) or other validated assessment tools for measuring pain intensity during the use of TENS)

3. Frequency of pain episodes

* We aim to present data at two to four weeks and after four weeks post intervention. For long-term usage (e.g. for a period of one month) we will consider the outcome measures up to three months. We will consider pain relief as moderate (at least 30\% pain relief over baseline) or substantial (at least $50 \%$ pain relief over baseline) as defined by IMMPACT guidelines (Dworkin 2008).

\section{Secondary outcomes}

1. Changes in consumption of analgesic and opioids during pain episodes

2. Changes in quality of life (QoL) (as measured by a validated scale)

3. Ability to cope with the activities of daily living (ADL)

4. Adverse effects of the intervention

\section{Search methods for identification of studies}

We will search for all relevant published and unpublished trials without restrictions on language, year or publication status.

\section{Electronic searches}

Relevant studies will be identified from the Cystic Fibrosis and Genetic Disorders Group's Haemoglobinopathies Trials Register, using the search terms: (sickle cell OR (haemoglobinopathies AND general)) AND transcutaneous electrical nerve stimulation [TENS].

The Haemoglobinopathies Trials Register is compiled from electronic searches of the Cochrane Central Register of Controlled Trials (CENTRAL) (updated each new issue of the Cochrane Library) and weekly searches of MEDLINE. Unpublished work is identified by searching the abstract books of five major conferences: the European Haematology Association conference; the American Society of Hematology conference; the British Society for Haematology Annual Scientific Meeting; the Caribbean Health Research Council Meetings; and the National Sickle Cell Disease Program Annual Meeting. For full details of all searching activities for the register, please see the relevant section of the Cochrane Cystic Fibrosis and Genetic Disorders Group's website.

We will search the following databases (Appendix 2):

- Embase (Ovid, 1974 onwards);

- PubMed (https://www.ncbi.nlm.nih.gov/pubmed, 1946 onwards).

In addition, we will search the following trial registries and other resources (Appendix 2):
- US National Institutes of Health Ongoing Trials Register, ClinicalTrials.gov (https://clinicaltrials.gov/);

- WHO ICTRP register (http://apps.who.int/trialsearch/);

- ISRCTN (http://www.isrctn.com/);

- Google Scholar (https://scholar.google.co.uk/).

Regarding our use of Google Scholar, we will perform a Google Scholar Advanced search, sort the results based on relevance, and screen the first 100 search results for relevant studies.

\section{Searching other resources}

For assistance in identifying ongoing or unpublished studies, we will contact study authors who have conducted prominent research in the relevant field regarding their ongoing studies or other relevant papers which may be eligible for inclusion.

We will search research papers which cannot be directly included in this review (observational studies, systematic and narrative reviews, conference reports, etc.) for the citations of relevant studies which can be included. These papers will then be sought and assessed for possible inclusion.

Organisations that we will attempt to contact to request suggestions for studies are:

- NCCIH formerly known as NCCAM;

- Foundation for Alternative and Integrative Medicine;

- American Alternative Medical Association;

- The Complementary and Natural Healthcare council;

- International Alternative Medical Association;

- The Association for Applied Psychophysiology and Biofeedback (formerly the Biofeedback Society of America).

Regarding grey literature, studies have shown that published studies often overestimate outcomes, compared to grey literature articles (Hopewell 2007). Moreover, exclusion of grey literature can result in systematic error, thus seriously threatening the validity of a systematic review (McAuley 2000). Therefore, to avoid this risk of publication bias, we will search grey literature databases in our attempt to identify relevant studies and authors from conference proceedings. We propose to search the following databases (recommended in the Cochrane Handbook For Systematic Reviews of Interventions) for unpublished reports or articles which may be appropriate for inclusion in this systematic review (Higgins 2011a):

- OpenGrey (www.opengrey.eu/);

- PsychEXTRA (www.apa.org/psycextra/);

- The Grey Literature Report (http://greylit.org/);

- The Agency for Healthcare Research and Quality ( www.ahrq.gov/);

- MedNar (http://mednar.com/mednar/desktop/en/ search.html).

\section{Data collection and analysis}




\section{Selection of studies}

Two review authors (SP, MG) will independently assess the eligibility of the trials identified by the literature searches by completing a trial selection form that will be designed in accordance with the inclusion criteria. Each author will independently evaluate each title for inclusion. If we do not find the relevant information in the abstract, we will retrieve the relevant full text report(s), if published, in order to complete this task. The authors will select the trials approved by both authors for inclusion in the review. In the case of any discrepancies relating to eligibility, a third author (SKB) will arbitrate. We will tabulate the excluded trials under 'Characteristics of excluded studies' and reasons will be given for the exclusion. The review authors will be unmasked to the trial authors, institutions and trial results during their assessments. We will produce a PRISMA chart as a systematic illustration of the entire trial selection process.

\section{Data extraction and management}

Two review authors (SP, SM) will independently and simultaneously extract data from the selected articles and this will be verified by two or three review authors with an aim to resolve any disagreements by discussion and consensus.

We will extract data using a standardised, pre-tested data extraction form. We will design the data extraction form through a collaboration of the review authors, and then pilot test this using a sample RCT and a quasi-RCT to ensure practical functionality. We will extract the following information from the included studies.

\section{Trial characteristics and source}

- Trial identifier (ID) - to be created by the review author

- Report ID - to be created by the review author

- Citation

- Contact details

\section{Methodology}

- Trial design

- Trial time and duration

- Setting

- Randomisation

- Allocation sequence concealment

- Type of blinding used

- Concerns about bias

- Intention-to-treat analysis

\section{Participants}

- Total number

- Eligibility criteria
- Age and gender of participants

\section{Interventions (TENS and variants)}

- Total number of intervention groups

\section{For each intervention and comparison group of interest}

- Electrode position

- Professional discipline of the clinician delivering TENS

- Frequency and intensity of the electrical current applied through the TENS device

- Frequency of administration

- Duration of administration

- Co-intervention(s)

\section{Outcome measures}

\section{For each outcome of interest}

- Outcome definition

- Units of measurement (if relevant)

- For scales, state upper and lower limits, and the interpretation of the scale

\section{Results}

- Number of participants allocated to each intervention group

\section{For each outcome of interest}

- Sample size

- Missing participants

- Summary data for each intervention group (mean and standard deviation for continuous data, $2 \times 2$ contingency table for dichotomous data, etc.)

\section{Assessment of risk of bias in included studies}

Two review authors (RD, SM) will independently assess the risk of bias of the included studies by using the criteria outlined in chapter 8 of the Cochrane Handbook for Systematic Reviews of Interventions (Higgins 2011b).

Each study will be assessed according to the following five components.

1. Random sequence generation (selection bias)

2. Allocation concealment (selection bias)

3. Masking (blinding) of participants and personnel (performance bias), and masking of outcome assessment

4. Incomplete outcome data (attrition bias) through withdrawals, dropouts and protocol deviations; and 
5. Selective reporting bias

We will also assess for any other sources of bias as reported in the Cochrane Handbook for Systematic Reviews of Interventions (bias related to the specific study design, early or abrupt end of studies, fraudulent studies) (Higgins 2011b). For each of the mentioned components, we will assign judgements of either low, unclear or high risk of bias.

We will record the results in the standard table provided in the Review Manager software (RevMan 2014), and will summarize the findings in a 'Risk of bias' table or graph. We aim to resolve any concerns or issues by discussion with a third review author (ALA). We will address the implications of the 'Risk of bias' assessment in the discussion section.

\section{Measures of treatment effect}

We will analyse and present dichotomous data, such as need for daily analgesic consumption between pain events, and ability to cope with ADL using the risk ratios (RR) with $95 \%$ confidence intervals (CIs). We will report adverse effects of the intervention with $99 \%$ CI to avoid errors due to multiple statistical testing. We will analyse and present continuous data, such as dose of analgesic consumption between pain events, pain relief and pain intensity as assessed by visual analogue pain scale score (on a scale of 0 to 10$)$, improvements in quality of life ( $\mathrm{QoL})$, using the mean differences (MD) (if outcomes are measured using the same scales) along with their $95 \%$ CIs. If outcomes are measured using different scales, we will use the standardised MD (SMD) and corresponding 95\% CIs.

We will analyse and present count data, such as frequency of pain episodes using the MD, which they will calculate by comparing the difference in the mean number of events in the intervention group as compared to the control group. If they are rare events, we will present the results using the rate ratio with $95 \%$ CIs.

Where meta analysis is not possible, we will present a narrative summary along with tabulated data.

\section{Unit of analysis issues}

The unit of analysis in this review will be the individual with SCD. Results of any identified cluster-randomised studies will be reported separately.

Regarding cross-over trials, as we are currently unaware of the longterm effects of these interventions, we are unable to determine whether the effects of the first intervention will interfere with those of the second. In order to avoid introducing this bias into the analysis, we will include only first-arm data from cross-over trials, when available.

If we identify trials with multiple treatment arms, we will only include those treatment arms whose parameters are minimally different from other included trials.

\section{Dealing with missing data}

We will contact trial authors to request access to the missing data regarding methods, participants, interventions and outcomes. In cases of missing data due to participant drop out we will conduct a primary analysis based on participants for whom complete data are available, provided that the total number of randomised participants and the number of dropouts to follow-up are well documented. We assume that missing outcomes will not be a problem if loss-to-follow-up is well documented, and is unrelated to outcomes in both trial arms, as per chapter 16 of the Cochrane Handbook for Systematic Reviews of Interventions (Higgins 2011a). However, if the reasons for why the data are missing are not available, we will document the possible effects of the missing participants through a sensitivity analysis.

\section{Assessment of heterogeneity}

In order to deal with clinical heterogeneity, studies that examine similar interventions will be pooled together. We will perform separate analyses for TENS compared to conventional treatment and TENS compared to placebo TENS or other non-pharmacological treatment. If we identify substantial (or higher) heterogeneity, and provided there are sufficient data, then we will undertake subgroup analyses according to the pre-planned comparisons described in the section 'Subgroup analysis and investigation of heterogeneity'. We will use the $\mathrm{Chi}^{2}$ test for assessing heterogeneity (significance level: $\mathrm{P}<0.1$ ). We will quantify the degree of heterogeneity using the $\mathrm{I}^{2}$ statistic (Deeks 2008). The guidelines for interpretation of the $\mathrm{I}^{2}$ values will be as follows.

- $0 \%$ to $40 \%$ indicates unimportant levels of heterogeneity

- $30 \%$ to $60 \%$ indicates moderate heterogeneity

- $50 \%$ to $90 \%$ indicates substantial heterogeneity

- $75 \%$ to $100 \%$ indicates considerable heterogeneity

We will also consider a visual inspection of the forest plot to identify whether CIs overlap.

\section{Assessment of reporting biases}

As we anticipate the inclusion of trials from the grey literature, it is particularly important for us to conduct an assessment of publication bias. If we identify at least 10 trials for inclusion in a metaanalysis, we will explore potential publication bias by generating a funnel plot and performing Egger's test to determine the degree of asymmetry (Egger 1997). If the included trials differ in sample size then we will visually inspect the funnel plots to explore the possibility of reporting biases. The results of Egger's test will also be interpreted cautiously due to the presence of many limitations in quantifying possible reporting biases (Moore 2008). We will address the implications of the publication bias assessment on the review findings in the discussion section. 


\section{Data synthesis}

We will synthesize the quantitative data compiled using the data extraction forms using a meta-analysis. We will use continuous data to calculate a MD or SMD for use in the meta-analysis, depending on the scales of measurement used in the trials (according to the reasoning in 'Measures of treatment effect'). We will calculate the appropriate measure of association (e.g. RR) for estimation of relative risk using categorical data. The summary measures will be pooled as appropriate, according to the scales used in different trials. We will calculate the $\mathrm{I}^{2}$ statistic to determine statistical heterogeneity, and thus determine whether a fixed-effect model (negligible heterogeneity), or a random-effects model (non-negligible heterogeneity) should be used for the meta-analysis (DerSimonian 1986). The results of the meta-analysis will be reported as pooled effect estimates, stated with 95\% CIs and illustrated graphically in a forest plot.

If meta-analysis cannot be undertaken for a particular outcome (due to an insufficient number of studies, or any other reason), we will include reasoning for this, as well as a narrative discussion of the available evidence relevant to the outcome variable in question.

\section{Subgroup analysis and investigation of heterogeneity}

If we identify substantial (or higher) statistical heterogeneity we plan the following subgroup analysis investigating the possible effect of TENS based on:

- age groups (below 18 years of age, 18 years and over);

- gender (male, female);

- stimulation parameters (e.g. high stimulation frequency

with low intensity, low frequency with a high stimulus intensity);

- frequency of administration of TENS (e.g. daily or not on a daily basis);

- duration of treatment with TENS (e.g. 30-minute sessions or more than 30 minutes).

\section{Sensitivity analysis}

We will assess the robustness of our findings by performing sensitivity analyses according to Cochrane recommendations where appropriate (Deeks 2011). If there are sufficient comparable trials, i.e. 10 or more, we will perform sensitivity analyses to study the effect of excluding trials with high risks of bias due to inadequate allocation of concealment, blinding, randomisation method or level of dropouts. Furthermore, we will also consider the impact of using a fixed-effect model compared to a random-effects model.

\section{Summary of findings table}

We will use the GRADE approach to create a 'Summary of findings' table, as suggested in chapters 11 and 12 of the Cochrane Handbook for Systematic Reviews of Interventions (Schünemann 2011a; Schünemann 2011b). The table will present the trial population and setting, the type of intervention and control group, the outcome measures listed below and an assessment of the evidence quality (as measured by the GRADE approach).

We will use the GRADE approach to rate the quality of the evidence as 'high', 'moderate', 'low', or 'very low' using the five GRADE considerations.

1. Risk of bias: serious or very serious

2. Inconsistency: serious or very serious

3. Indirectness: serious or very serious

4. Imprecision: serious or very serious

5. Publication bias: likely or very likely

We will generate a separate 'Summary of findings' table for each comparison with the following outcomes:

- pain relief;

- pain intensity as assessed by VAS or any other validated pain score;

- frequency of pain episodes;

- changes in consumption of analgesics and opioids during pain episodes;

- changes in QoL (as measured by a validated scale);

- changes in ability to cope with the ADL;

- adverse effects of the intervention.

\section{ACKNOWLEDGEMENTS}

We would like to thank:

Tracey Remmington, Managing Editor, Cochrane Cystic Fibrosis and Genetic Disorders Review Group for providing guidance in drafting the protocol;

Sarah Nevitt, Group Statistician, Cochrane Cystic Fibrosis and Genetic Disorders Review Group for providing guidance in drafting the protocol;

Natalie Hall, Information Specialist, Cochrane Cystic Fibrosis and Genetic Disorders Review Group, for comments on the search strategy.

We are very grateful to Professor Datuk Dr Abdul Razzak Chief Executive of Melaka-Manipal Medical College, Malaysia and Professor Dr Jaspal Singh, Dean, Faculty of Medicine, Melaka-Manipal Medical College, Malaysia for their constant support, constructive comments and encouragement in writing this protocol.

This project was supported by the National Institute for Health Research, via Cochrane Infrastructure funding to the Cochrane Cystic Fibrosis and Genetic Disorders Group. The views and opinions expressed therein are those of the authors and do not necessarily reflect those of the Systematic Reviews Programme, NIHR, NHS or the Department of Health. 


\section{R E F E R E N C E S}

\section{Additional references}

\section{American Pain Society Guidelines 1999}

Benjamin LJ, Dampier CD, Jacox AK, Odesina V, Phoenix D, Shapiro, B, et al. Guideline for the Management of Acute and Chronic Pain in Sickle-Cell Disease, APS Clinical Practice Guidelines Series, No. 1. American Pain Society 1999.

Ballas 2005

Ballas SK. Pain management of sickle cell disease. Hematology/Oncology Clinics of North America 2005;19(5): 785-802.

Ballas 2012

Ballas SK, Gupta K, Adams-Graves P. Sickle cell pain: a critical reappraisal. Blood 2012;120(18):3647-56.

\section{Ballas 2014}

Ballas SK. Pathophysiology and principles of management of the many faces of the acute vaso-occlusive crisis in patients with sickle cell disease. European Journal of Haematology 2014;95(2):113-23.

Barbedo 1974

Barbedo MM, McCurdy PR. Red cell life span in sickle cell trait. Acta Haematologica 1974;51(6):339-43.

\section{Bennett 2011}

Bennett MI, Hughes N, Johnson MI. Methodologicalquality in randomised controlled trials of transcutaneous electric nerve stimulation for pain: low fidelity may explain negative findings. Pain 2011;152(6):1226-32.

Brosseau 2003

Brosseau L, Yonge KA, Robinson V, Marchand S, Judd M, Wells G, et al. Transcutaneous electrical nerve stimulation (TENS) for the treatment of rheumatoid arthritis in the hand. Cochrane Database of Systematic Reviews 2003, Issue 3. [DOI: 10.1002/14651858.CD004377]

Brozovic 1987

Brozovic M, Davies SC. Management of sickle cell disease. Postgraduate Medical Journal 1987;63:605-9.

\section{Buchanan 2005}

Buchanan ID, Woodward M, Reed GW. Opioid selection during sickle cell pain crisis and its impact on the development of acute chest syndrome. Pediatric Blood \& Cancer 2005;45(5):716-24.

\section{David 2010}

Rees DC, Williams TN, Gladwin MT. Sickle-cell disease. Lancet 2010;376(9757):2018-31.

\section{Deeks 2008}

Deeks JJ, Altman DG, Bradburn MJ. Chapter 15: Statistical methods for examining heterogeneity and combining results from several studies in meta analysis. Systematic Reviews in Health Care: Meta-Analysis in Context http:// onlinelibrary.wiley.com/doi/10.1002/9780470693926.ch15/ summary. BMJ Publishing Group, London, UK, (accessed 23 June 2016).
Deeks 2011

Deeks JJ, Higgins JPT, Altman DG on behalf of the Cochrane Statistical Methods Group. Chapter 9: Analysing data and undertaking meta-analysis. In: Higgins JPT, Green S, editor(s). Cochrane Handbook for Systematic Reviews of Interventions Version 5.1.0 [updated March 2011]. The Cochrane Collaboration, 2011. Available from www.cochrane-handbook.org 2011.

\section{DerSimonian 1986}

DerSimonian R, Laird N. Meta-analysis in clinical trials. Contemporary Clinical Trials 1986;7(3):177-88.

\section{DeSantana 2008}

DeSantana JM, Santana-Filho VJ, Sluka KA. Modulation between high-and low-frequency transcutaneous electric nerve stimulation delays the development of analgesic tolerance in arthritic rats. Archives of Physical Medicine and Rehabilitation 2008;89(4):754-60.

\section{Dworkin 2008}

Dworkin RH, Turk DC, Wyrwich KW, Beaton D, Cleeland $\mathrm{CS}$, Farrar JT, et al. Interpreting the clinical importance of treatment outcomes in chronic pain clinical trials: IMMPACT recommendations. Journal of Pain 2008;9(2): 105-21.

\section{Egger 1997}

Egger M, Smith GD, Schneider M, Minder C. Bias in meta-analysis detected by a simple, graphical test. BMJ 1997;315(7109):629-34.

\section{Gibson 2015}

Gibson W, Wand BM, O'Connell NE. Transcutaneous Electrical Nerve Stimulation (TENS) for neuropathic pain in adults. Cochrane Database of Systematic Reviews 2015, Issue 11. [DOI: 10.1002/14651858.CD011976]

Higgins 2011a

Higgins JPT, Green S, editor(s). Cochrane Handbook for Systematic Reviews of Interrventions Version 5.1. 0 (updated March 2011). The Cochrane Collaboration, 2011. Available from handbook.cochrane.org.

\section{Higgins 2011b}

Higgins JPT, Altman DG, Sterne JAC on behalf of the Cochrane Statistical Methods Group and the Cochrane Bias Methods Group, editor(s). Chapter 8: Assessing risk of bias in included studies. In: Higgins JPT, Green S editor(s). Cochrane Handbook for Systematic Reviews of Interventions. Version 5.1.0 (updated March 2011) The Cochrane Collaboration, 2011. Available from handbook.cochrane.org.

\section{Hopewell 2007}

Hopewell S, McDonald S, Clarke M, Egger M. Grey literature in meta-analyses of randomised trials of health care interventions. Cochrane Database of Systematic Reviews 2007, Issue 2. [DOI: 10.1002/14651858.MR000010.pub3]

\section{Hurlow 2012}

Hurlow A, Bennett MI, Robb KA, Johnson MI, Simpson $\mathrm{KH}$, Oxberry SG. Transcutaneous electric nerve stimulation 
(TENS) for cancer pain in adults. Cochrane Database of Systematic Reviews 2012, Issue 3. [DOI: 10.1002/ 14651858.CD006276.pub3]

\section{Johnson 2010}

Johnson MI, Walsh DM. Pain: continued uncertainty of TENS' effectiveness for pain relief. Nature Reviews Rheumatology 2010;6(6):314-6.

Kaye 2015

Vladimir K, Murray EB. Transcutaneous electrical nerve stimulation. http://emedicine.medscape.com/article/ 325107 (accessed 23 June 2016).

\section{Kocyigit 2012}

Kocyigit F, Akalin E, Gezer NS, Orbay O, Kocyigit A, Ada E. Functional magnetic resonance imaging of the effects of low-frequency transcutaneous electrical nerve stimulation on central pain modulation: a double-blind, placebocontrolled trial. Clinical Journal of Pain 2012;28(7):581-8.

Kroeling 2013

Kroeling P, Gross A, Graham N, Burnie SJ, Szeto G, Goldsmith $\mathrm{CH}$, et al. Electrotherapy for neck pain. Cochrane Database of Systematic Reviews 2013, Issue 8. [DOI: 10.1002/14651858.CD004251.pub5]

\section{McAuley 2000}

McAuley L, Tugwell P, Moher D. Does the inclusion of grey literature influence estimates of intervention effectiveness reported in meta-analyses?. Lancet 2000;356(9237): $1228-31$.

Melzack 1965

Melzack R, Schecter Bayla. Itch and vibration. Science 1965;147(3661):1047-8.

\section{Milne 2004}

Milne S, Welch V, Brosseau L, Saginur M, Shea B, Tugwell $\mathrm{P}$, et al. Transcutaneous electrical nerve stimulation (TENS) for chronic low-back pain. Cochrane Database of Systematic Reviews 2004, Issue 2. [DOI: 10.1002/ 14651858.CD003008.pub2]

\section{Moore 2008}

Moore RA, Barden J, Derry S, McQuay HJ. Managing potential publication bias. Systematic Reviews in Pain Research: Methodology Refined 2008;1:15-23.

\section{Neville 2011}

Neville AK, Panepinto JA. Pharmacotherapy of sickle cell disease. World Health Organization 18th Expert Committee on the Selection and Use of Essential Medicines. 2011.

Niscola 2009

Niscola P, Sorrentino F, Scaramucci L, De Fabritiis P, Cianciulli P. Pain syndromes in sickle cell disease: an update. Pain Medicine 2009;10(3):470-80.

\section{Platt 1991}

Platt OS, Thorington BD, Brambilla DJ, Milner PF, Rosse WF, Vichinsky E, et al. Pain in sickle cell disease: rates and risk factors. New England Journal of Medicine 1991;325(1): $11-6$.

\section{RevMan 2014 [Computer program]}

The Nordic Cochrane Centre, The Cochrane Collaboration. Review Manager (RevMan). Version 5.3. Copenhagen: The Nordic Cochrane Centre, The Cochrane Collaboration, 2014.

Rutjes 2009

Rutjes AW, Nüesch E, Sterchi R, Kalichman L, Hendriks E, Osiri M, et al. Transcutaneous electrostimulation for osteoarthritis of the knee. Cochrane Database of Systematic Reviews 2009, Issue 4. [DOI: 10.1002/ 14651858.CD002823.pub2]

\section{Sluka 2013}

Sluka KA, Bjordal JM, Marchand S, Rakel BA. What makes transcutaneous electrical nerve stimulation work? Making sense of the mixed results in the clinical literature. Physical Therapy 2013;93(10):1397-402.

\section{Smith 2005}

Smith WR, Bovbjerg VE, Penberthy LT, McClish DK, Levenson JL, Roberts JD, et al. Understanding pain and improving management of sickle cell disease: the PiSCES study. Journal of the National Medical Association 2005;97 (2):183-93.

\section{Stinson 2003}

Stinson J, Naser B. Pain management in children with sickle cell disease. Pediatric Drugs 2003;5(4):229-41.

\section{Sunshine 1996}

Sunshine W, Field TM, Quintino O, Fierro K, Kuhn C, Burman I, et al. Fibromyalgia benefits from massage therapy and transcutaneous electrical stimulation. Journal of Clinical Rheumatology 1996;2(1):18-22.

\section{Weatherall 2001}

Weatherall DJ, Clegg JB. Inherited haemoglobin disorders: an increasing global health problem. Bulletin of the World Health Organization 2001;79(8):704-12.

\section{WHO 2015}

World Health Organization. Genomicresource centre. Genes and human disease monogenic diseases - sickle cell anaemia. www.who.int/genomics/public/geneticdiseases/ en/index 2.html. World Health Organisation, (accessed prior to 09 January 2017).

* Indicates the major publication for the study 
A P PENDICES

\section{Appendix I. Glossary}

\begin{tabular}{|c|c|}
\hline Term & Definition \\
\hline Afferent input & $\begin{array}{l}\text { Information from our sensory organs (e.g. eye, skin) transmitted as input to the central nervous system } \\
\text { (brain, spinal cord) }\end{array}$ \\
\hline Avascular necrosis & $\begin{array}{l}\text { Cellular death of bone components due to interruption of the blood supply; the bone structures then collapse, } \\
\text { resulting in bone destruction, pain, and loss of joint function }\end{array}$ \\
\hline Endogenous & Originating or developing from within the body. \\
\hline Haemolysis & $\begin{array}{l}\text { The destruction of red blood cells which leads to the release of hemoglobin from within the red blood cells } \\
\text { into the blood plasma }\end{array}$ \\
\hline Hypersplenism & A condition in which the spleen becomes increasingly active and then rapidly removes the blood cells \\
\hline Neuropathic & Due to disease of nerves. \\
\hline Nociceptive & $\begin{array}{l}\text { Of, relating to, or denoting, pain arising from the stimulation of nerve cells (often as distinct from that } \\
\text { arising from damage or disease in the nerves themselves) }\end{array}$ \\
\hline Non-invasive & Not requiring the introduction of instruments into the body. \\
\hline Pharmacogenomics & $\begin{array}{l}\text { The use of human genetic variations to optimise the discovery and development of drugs and the treatment } \\
\text { of patients }\end{array}$ \\
\hline Presynaptic inhibition & Refers to a decrease of transmitter release at central synapses \\
\hline TIA & Transient ischaemic attack caused by a temporary disruption in the blood supply to part of the brain \\
\hline
\end{tabular}

\section{Appendix 2. Electronic searches}

\begin{tabular}{ll}
\hline Database/ Resource & Strategy \\
\hline PubMed (1946 onwards) & $\begin{array}{l}\text { (sickle OR “Anemia, Sickle Cell”[Mesh]) AND (“Transcutaneous electric” OR “Transcutaneous } \\
\text { electrical” OR “Transcutaneous Electric Nerve Stimulation”[Mesh]) }\end{array}$ \\
\hline Embase (Ovid 1974 - to present) & $\begin{array}{l}1 \text { exp Sickle Cell Anemia/ } \\
2 \text { sickle.tw. } \\
31 \text { OR 2 } \\
4 \text { Transcutaneous electric* nerv* stimulation.tw. }\end{array}$ \\
\hline
\end{tabular}

Transcutaneous electrical nerve stimulation (TENS) for pain management in sickle cell disease (Protocol) 


\begin{tabular}{|c|c|}
\hline & $\begin{array}{l}5 \text { TENS.tw. } \\
6 \text { Transcutaneous Electrical Nerve Stimulation/ } \\
7 \text { (4 OR } 5 \text { OR 6) } \\
8 \text { (3 AND 7) }\end{array}$ \\
\hline Clinicaltrials.gov & $\begin{array}{l}\text { [ADVANCED SEARCH] } \\
\text { STUDY TYPE: Interventional Studies } \\
\text { CONDITIONS: sickle } \\
\text { INTERVENTIONS: transcutaneous OR TENS }\end{array}$ \\
\hline WHO ICTRP & $\begin{array}{l}\text { Two separate searches will be carried out: } \\
\text { SEARCH 1: sickle AND transcutaneous } \\
\text { SEARCH 2: sickle AND TENS }\end{array}$ \\
\hline ISRCTN Registry & $\begin{array}{l}\text { [ADVANCED SEARCH] } \\
\text { CONDITION: sickle } \\
\text { INTERVENTIONS: transcutaneous OR TENS }\end{array}$ \\
\hline Google Scholar & $\begin{array}{l}\text { sickle AND ("transcutaneous electric" OR "transcutaneous electrical" OR tens) } \\
\text { NOTE: The results will be sorted by "relevance" and the first } 100 \text { results screened for relevant } \\
\text { studies }\end{array}$ \\
\hline Grey Literature Databases & $\begin{array}{l}\text { Two separate searches of each database will be carried out: } \\
\text { SEARCH 1: sickle AND transcutaneous } \\
\text { SEARCH 2: sickle AND TENS }\end{array}$ \\
\hline
\end{tabular}

\section{CONTRIBUTIONS OFAUTHORS}

The following potential contributions of authors to each section of the review are described below.

- Conceiving the review: Cochrane Cystic Fibrosis and Genetic Disorders Review Group

- Designing the review: SP, RD, MG

- Coordinating the review: SP, RD

. Writing the background, objectives and inclusion criteria sections: SP, MG

- Data collection for the review: SP, MG

· Designing search strategies: SP. ALA, SM, MG

- Undertaking searches: SP, MG, SR

- Screening search results: SP, MG

- Organizing retrieval of papers: SP, MG, SM

- Screening retrieved papers against eligibility criteria: SP, MG, UAY

- Appraising quality of papers: SKB

- $\quad$ Extracting data from papers: SP, SM

Writing to authors of papers for additional information: SP, MG

Transcutaneous electrical nerve stimulation (TENS) for pain management in sickle cell disease (Protocol)

Copyright @ 2017 The Cochrane Collaboration. Published by John Wiley \& Sons, Ltd. 
- Providing additional data about papers: Cochrane Cystic Fibrosis and Genetic Disorders Review Group

- Obtaining and screening data on unpublished studies: SP, MG

- Data management for the review: SM, ALA

- $\quad$ Entering data into RevMan: SP, SM, MG, ALA

- Analysis of data: SP, SM, MG, ALA

- Interpretation of data: SP, SM, MG, ALA

- Providing a methodological perspective: ALA, SP

- Providing a clinical perspective: SKB, UAY

. Writing the review (or protocol): SP, MG

- Providing general advice on the review: SKB, UAY

\section{DECLARATIONSOF INTEREST}

All authors: none known.

\section{SOURCES OF SUPPORT}

\section{Internal sources}

- University of Liverpool, UK.

\section{External sources}

- The National Institute for Health Research (NIHR), UK.United Kingdom Cochrane Centre, UK. 